\title{
Analysis of Innovative Approaches in the Class using Conceptual Maps and Considering the Learning Styles of Students
}

\author{
Coma T., Aguelo A., Álvarez P., Sanz C., Member, IEEE, Baldassarri S., Senior Member, IEEE
}

\begin{abstract}
This paper presents innovations to stimulate the autonomy of engineering students by using different active methodologies. The strategies designed to address this problem are based on analyzing students' learning styles and incorporating specific tools into teaching practice, such as "M-eRoDes", which supports the automatic evaluation and feedback of concept maps created by them. Among the main findings, the students' assessment of the activity "making concept maps" stands out as useful but not easy. Despite the difficulty, or precisely for that reason, the experience has contributed to improve their autonomy and to develop skills to express the knowledge they have learned.
\end{abstract}

Index Terms - computer science education, educational technology, learning management systems, semantic web, concept maps

\section{INTRODUCTION}

$\mathrm{M}$ ANY SUBJECTS taught in Engineering courses propose activities that encourage students to learn autonomously [1]. As part of these activities, students are asked to look for information on the Web, perform a critical analysis of the contents found, process these contents and, finally, present their learnings in a final document. This last task is complex because it forces students to contextualize and reflect upon what they learned, abstract relevant information, and look for a coherent way to express the new knowledge. Usually, the end result is a written technical memory or an oral dissertation presented and discussed in front of their classmates.

T. Coma. Ph.D. degree in Psychology and Learning, Psychology and Sociology Department, University of Zaragoza, Spain (e-mail: tcoma@unizar.es) (https://orcid.org/0000-0002-7439-8459)

A. Aguelo. Ph.D. degree in Sociology, Psychology and Sociology Department, University of Zaragoza, Spain (e-mail: aaguelo@unizar.es). (https://orcid.org/0000-0002-8118-1012)

P Alvarez. PhD degree in Computer Science, Department of Informatics and System Engineering, University of Zaragoza, Spain (e-mail: alvaper@unizar.es) (https://orcid.org/0000-0002-6584-7259)

C. Sanz. Ph.D. degree in Computer Science, Institute of Research in Computer Science III-LIDI, Computer Science School, National University of $\mathrm{La}$ Plata. Associate Researcher of CIC, Argentine (e-mail: csanz@lidi.info.unlp.edu.ar) (https://orcid.org/0000-0002-9471-0008)

S. Baldassarri. $\mathrm{PhD}$ degree in Computer Science, Department of Informatics and System Engineering, University of Zaragoza, Spain (e-mail: sandra@unizar.es) (https://orcid.org/0000-0002-9315-6391).

DOI (Digital Object Identifier)
From the point of view of non-technical training in Engineering, students should experience the process of preparing a document or creating a presentation. However, this is meaningful only if they receive immediate feedback from teachers to help them reflect upon their own performance. When there is a large number of students or the curriculum includes many activities of this type, assessment and feedback tasks become impractical. Nevertheless, it is essential that students understand if they have achieved the goal of the activity and whether they are capable of correctly expressing and communicating what they learned.

These issues have motivated educators to seek alternative evaluation procedures, mainly automated ones, where their responsibilities are monitoring and accompanying the development of the learning process.

In an optional course, offered to last year students of Computer Engineering, a series of activities have been planned and implemented with the aim of encourage students' autonomy. These activities involve students' participation both individually and in groups. To this end, an automatic evaluation system based on the use of conceptual maps as student knowledge representation model was developed. This evaluation method applies semantic techniques to calculate a number of learning indicators; and it has been built into an online learning tutor called M-eRoDes. This tutor was developed by the authors as part of a previous work [2]. The use of conceptual maps presents certain difficulties to students when they need to represent the knowledge they have acquired. However, the experience showed the usefulness of the learning indicators that were calculated, encouraging students to reflect upon their own learning process.

On the other hand, it was observed that not all students learn in the same way, and not all of them have the same ability to express and represent their ideas. This has steered us into considering a potential correlation between learning styles and student performance in the representation activities proposed in the context of the learning process.

Therefore, in this paper, we consider the integration of conceptual maps in the teaching and learning process of Engineering students, and its suitability as knowledge representation and evaluation tool is analyzed based on the students' learning styles. To evaluate the conceptual maps and for giving automatic feedback to the students, $M$-eRoDes is used. Moreover, the work carried out in [3] is extended, presenting other eleven activities proposed by teachers. The ease-of-use and usefulness of conceptual maps are compared 
to the other activities, for a more accurate understanding of students' opinion as regards the full proposal of the course, and to analyze these based on learning styles.

This paper is structured as follows: Section II includes comments on related works, Section III introduces the context and goals for this work; Section IV describes the experience, detailing scheduled activities; Section V presents the tools used to carry out the activities; Section VI discusses the results obtained for the various goals; and, finally, Section VII summarizes our conclusions and future lines of work.

\section{STATE OF THE ART}

In this section, existing works in three areas of interest for this article are presented: tutoring and learning applications, automatic evaluation systems used by these applications, and studies of the learning styles of students using these applications.

First, it should be noted that there are quite a few commercially available and open source platforms for learning management, such as Moodle, Blackboard or Canvas LMS, as well as software applications that act as intelligent online tutors $[4,5,6]$. Currently, all these solutions face the challenge of offering learning that is personalized and/or tailored to each student. This adaptability is offered on two different levels through contents, by suggesting different materials and exercises for the same task, thus adapting to the individual needs of each student [7], or through a learning itinerary, by personalizing the tasks that the student will have to carry out, and their level of difficulty, during the learning process itself [8]. Regardless of the customization method used, most learning systems make relevant decisions based solely on the results obtained by students in the evaluation tests. However, some works have studied the impact and the possibility of considering additional features of interest about the students to make these decisions, such as student personal and demographic profile [9], student emotions [10] and even student learning styles [11].

These personalization options should be integrated into the pedagogical model used by the learning platform or application. In general, existing solutions opt for a learning model based on problem solving. This learning model has widely proven its efficacy, but it is limited from the point of view of the type of activities that can be scheduled. For instance, none of the existing applications proposes learning based on collaborative techniques or team work, with the exception of the solution proposed in [12] for collaboratively solving medical cases.

The second issue of interest is how these applications assess student learning. In general, the evaluation tools offered are based on the use of different types of tests. Tests can easily be graded in an automatic way and offer quantitative, immediate feedback to the student. However, their cost measured in preparation time is high, and they are hard to use in combination with training evaluation methods. Research works have explored alternative techniques for automatic evaluation of learning, such as those based on knowledge representation and analysis using conceptual maps. These semantic techniques have been successfully tested in education [13] and, even though they have some issues related to the difficulty students have to express their knowledge using these maps [14], some solutions have already been proposed to facilitate their application (for instance, creating maps from text descriptions [15], or providing students with an empty structure of the map they should build, like a "fill-inthe-map" kind of activity).

The tools that are available for automatically evaluating learning based on the use of conceptual maps usually resort to two different analysis techniques: structural models [16, 17] and relational models $[18,19]$. Structural models are only applicable to hierarchical maps and assign a score to the solution based on the hierarchy of concepts that is represented (number of levels, number of concepts in each level, relations between concepts from different levels, etc.). On the other hand, relational models assign a score to the map based on its similarity with a reference map previously defined by the educator. This score usually takes into account the concepts and relations that are successfully discovered and identified. Regardless of the model, feedback offered to students after the evaluation is a key issue. As a disadvantage, feedback is usually a quantitative grade of the map and a comparison with the average grade obtained by classmates. As an exception, in the model described in [20], feedback includes the concepts and relations that students failed to discover.

Lastly, the third aspect of interest is that related to considering student learning style. Learning is essentially a change caused by experience [21], and this change does not happen in the same way for each and every student. From this perspective, the approach presented by Kolb [22, 23] is relevant, where learning is considered as a cycle that revolves around a two-axis process - grasping experience $(\mathrm{CE} / \mathrm{Concrete}$ Experience and AC/Abstract Conceptualization) and transforming experience (RO/Reflective Observation and AE/Active Experimentation). Behind each of the quadrants that are generated in these phases of the cycle (CE-RO-AC$\mathrm{AE})$ there is an underlying learning style. Depending on individual characteristics, there are process preferences that will result in students being able to perform more easily in those parts of the cycle that match their preferences. Taking this as a starting point, Kolb defined four typologies based on how the student prefers to work with the information: divergent, assimilator, convergent and accommodative.

Kolb [22] discusses the duality between being activereflective or being immediate-analyzing. In [24], this is applied to an approach to learning styles, which are defined as: "[...] cognitive, affective and physiological features that serve as relatively stable indicators of how students grasp, interact with and respond to their learning environments" [24, p.48]; and the authors define their CHAEA questionnaire with four possible learning styles based on Kolb's model: active (divergent), reflective (assimilator), theoretical (convergent) and pragmatic (accommodative). This approach is particularly relevant for this work, since there is a specific scale for Computer Science students [24] that allows categorizing group preferences. It should be noted that in a research work that 
relates CHAEA to learning strategies, the creation of conceptual maps is specifically mentioned as an activity of choice for the theoretical and pragmatic styles [25]. Therefore, this relation is used as an antecedent for our research.

On the other hand, in Felder and Silverman's [26] learning styles model, four two-pole scales are proposed: Active/Reflective, Sensing/Intuitive, Visual/Verbal and Sequential/Global. The research carried out by these authors in the context of Engineering show that students have a preference for the active, sensing, visual and global styles (in the case of more creative students).

These results do not match the data obtained in research studies carried out using CHAEA in the context of technical courses of studies (including Computer Science) as regards the preference for the active style. These studies show that this group of students have a low preference for the active style, and specifically recommend going for active experimentation instead [27, 28].

After analyzing the state of the art, it can be observed that the learning tutor developed and used in this experience is a novelty contribution as regards supported activity types (collaborative and team activities) and its automated, in-built assessment system (based on conceptual maps). On the other hand, a second contribution is the possibility of analyzing scheduled strategies and activities taking into account the learning styles of Computer Science students. These results can help understand the strengths and weaknesses of the didactic proposals being used.

\section{CONTEXT AND OBJECTIVES}

Since academic year 2014-2015, a number of didactic strategies and innovations centered on students have been implemented, in courses of the final year of the career of Computer Engineering, through three Teaching Innovation projects financed by the University of Zaragoza. These strategies propose the active involvement of students in the teaching and learning process, as well as promoting student autonomy and increasing motivation. In addition to the traditional theoretical lectures used to introduce basic concepts and laboratory practices to get hands-on experience with different computer tools currently used, various activities are proposed in which students have to produce their own learning resources, share them, and use them to learn. This approach is an alternative to the usual scenario, where the educator is responsible for preparing the resources used to teach and study.

Another key, innovative issue is the procedure used to evaluate activities. It is important that students receive immediate feedback related to how they are progressing in their learning. Given the number and diversity of activities that take place during the course, automatic and continuous evaluation was considered as part of the teaching strategy, also oriented to encourage autonomy.

The use of conceptual maps was proposed as knowledge representation element, and a relational assessment model was designed to calculate learning indicators using M-eRoDes [2]. However, the suitability of conceptual maps for the learning styles of the students participating in the course had not been considered in previous courses. This issue is relevant from the point of view of the validity that the learning indicators use may have. For this reason, the specific objectives related to this work are aligned with analyzing and correlating these variables, more specifically with:

1- Interpreting resulting learning indicators after applying the relational evaluation model proposed by the teaching staff. Analyzing these indicators is aimed at validating if the techniques used for building conceptual maps are appropriate for the profile of students attending the course, identifying potential problems in the learning process, and verifying if the metrics in the model truly represent what has been learned.

2- Identifying how the students value the friendliness and usefulness of the different activities proposed. This analysis also includes conceptual maps activities, specifically considered below.

3- Knowing and reflecting on, specifically, the assessment carried out by the students in relation to working with conceptual maps (CMs) as a tool to represent and evaluate the knowledge acquired during the learning process. In particular, we analyzed student opinions about the difficulties found when building the maps, the type of map used, whether the maps built reflected what they thought they had learned, as well as how useful this tool was for the assessment process.

4- Establishing the learning style of the students that participate in the course and identifying the preferred style for the current academic year. The basic characteristics of the preferred styles should help teachers consider if their activities proposal is appropriate for the profile of the students. On the other hand, the existence of a potential relation between students preferred activities and those tasks where they should feel more comfortable based on their preferred learning style will also be analyzed.

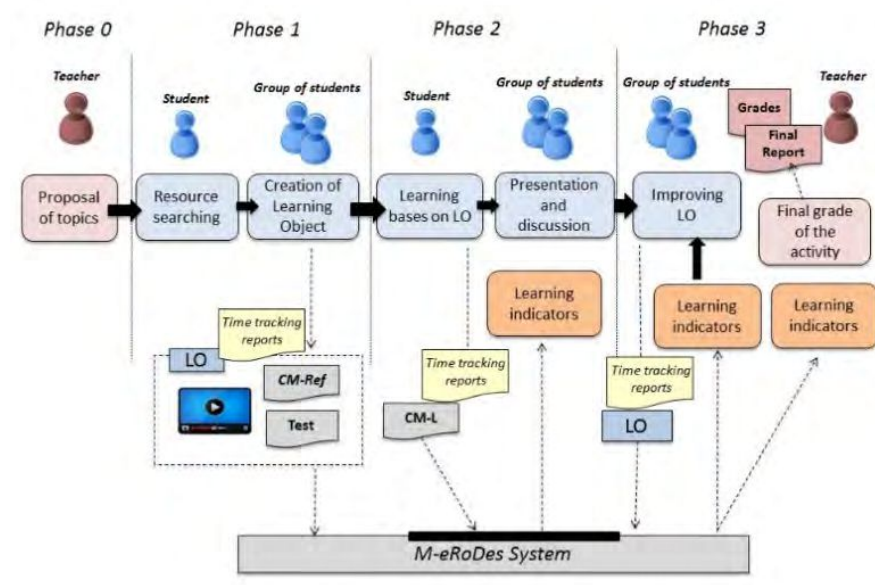

Fig. 1. Sequence of activities proposed 


\section{THE EXPERIENCE}

This innovation experience was carried out for the subject "User-Centered Design. Designing for Multimedia" (UCD). This is a mandatory course for the "Information Technology" specialization branch of the Computer Engineering higher course of studies. It is taught in the eighth semester. The number of enrolled students usually ranges from 15 to 20 per classroom. This subject, in particular, favors the implementation of the strategies proposed, since its contents include teaching how to work with multimedia resources. Therefore, the activity related to preparing learning resources turns out to be a specific use case of what the students are learning.

The subject proposes a run through different types of activities to help students taking last-year subjects, whose contents are in constant evolution, get actively involved in their learning process and achieve greater autonomy and improve their ability to express what they have learned.

Figure 1 shows the specific sequence of activities proposed, which combine team-work and individual work, going through the following phases:

- Phase 0: topic proposal and team creation. Usually, the teacher proposes different topics for which it would be interesting to develop a learning resource. Work teams consisting in groups of 2-3 students each are created, based on personal preferences. Each group must choose one of the topics proposed.

- Phase 1 (individual): search for contents and updated information.

- Phase 1 (team): learning resource creation. This includes creating a video and generating a test (Test) and a conceptual map (CM-Ref) on the contents of their own resource. This first version of the conceptual map is also reviewed by the educators.

- Phase 2 (individual): learning based on the resources created in the previous phase. This includes watching the videos created by classmates and taking the test and building a conceptual map for the contents of each of these resources (CM-L).

- Phase 2 (team): presentation and discussion of their work. After viewing the resources created by their classmates, each work is discussed in class. The team that created the resource clarifies any doubts, provides additional information, expands on the work, etc.

- Phase 3 (team): improvement of learning resources, which is done based on the feedback received from classmates and educators.

- Final 3 (educators): final evaluation of the activity and analysis of the learning indicators obtained by the students.

During phases 1, 2 and (part of) 3, the role of the educators is to provide advice and monitor students, both in practical sessions and in tutorial activities, either in person or through email consultation. It is not until the final phase of the activities that the educator evaluates student intermediate learning indicators and the end result obtained by each team.
Using that information, the educator is then able to grade (if necessary) the work carried out by the students, detect any issues that may have affected the process, and propose any corrective measures.

\section{TOOLS AND INSTRUMENTS USED}

In this section, we briefly describe the various tools used to carry out this innovation experience. First, we describe $M$-eRoDes, the software system used to schedule and carry out the different activities included in this proposal. Then, the instruments and methods used to study student learning styles are also described, as well as the different opinion surveys used for gathering data.

\section{A. M-eRoDes description}

Despite the wide variety of existing software applications, both commercial and for research, to schedule and manage teaching and learning activities [29], none of these solutions supports the activity models used in this innovation experience (for instance, to mediate the sequence of activities shown in Fig. 1). For this reason, the M-eRoDes system was developed, which is a service-oriented web tool that provides the necessary functionality to schedule and carry out learning activities based on active and collaborative methodologies [30]. From the point of view of the experience described in this paper, $M$-eRoDes allows semantically storing the learning resources created by the students, accessing them for learning activities, and automatically self-assessing such learning. In these processes, both semantics and conceptual maps play a key role, as described in the paragraphs below.

M-eRoDes includes a semantic repository of learning resources. Each time a new resource is stored in the system, it is semantically labeled based on its contents. This labeling process is automatic and allows contextualizing the resources from the standpoint of a domain ontology [31]. These labels favor classification and subsequent access to and use of the resources.

An additional key functionality offered by $M$-eRoDes is the possibility of scheduling learning activities based on the use of the resources available in its repository. The web interface of the system allows students to access the list of activities that they must complete during the course. A typical activity consists in accessing a learning resource, viewing its contents, and self-assessing by doing a test. An example of this type of basic activity would be the task scheduled in Phase 2 of the activity described in Fig. 1.

One of the most significant innovations in $M$-eRoDes is its evaluation system based on conceptual maps. The creator of a learning resource must express, using a conceptual map, the teaching objectives associated with the resource, as well as its key contents; i.e., what a student working with the resource should learn. This map is called a reference map, and it is stored in the system repository together with its resource. On the other hand, when students work with a resource, they must use a conceptual map, called learning map, to express what they think they have learned. The evaluation system automatically compares these two maps from the point of their 
contents, relations and significance in the context of the resource. This comparison is done by combining different semantic similarity and graph theory algorithms, and the results obtained are then interpreted to offer students a quantitative and qualitative assessment of their learning [13]. To make this interpretation easier, a simple color scale is used to help students identify those parts of the map that were successfully completed and those that need improvement. In addition to this, the system allows students to access their history of learning indicators, while educators have access to a history of the activities they have scheduled for students.

This self-assessment system requires students to be able to represent acquired knowledge (or knowledge that should be acquired) in a conceptual map. This task is not simple or intuitive in most cases [14]. For this reason, as part of the experience, two specific actions were scheduled. First, at the beginning of course, a class is offered to teach students a simple technique for creating conceptual maps. This methodological view is complemented with examples and simple exercises to help them understand how to approach the representation process. The class has a duration of 2 hours. As a second measure, every time students are required to create a conceptual map from scratch, the tool provides a list of concepts to help them prepare the corresponding knowledge structure. This list includes the concepts contained in the reference conceptual map used in the tool's automatic evaluation process.

Therefore, M-eRoDes allows educators to schedule the various learning activities and offers functionality to help students complete the tasks involved and evaluate the knowledge they acquired, as shown in Fig. 1. The tool's interface is simple and does not require any specific training. However, to help students use it, a class is offered as an introduction to M-eRoDes. This class has a duration of 1 hour, and its main goal is to make sure students know how to create new resources, work with existing ones, create conceptual maps, and interpret the learning indicators offered by the system. Additionally, the tool has an online help system as a supplement to this initial, basic training.

\section{B. Instruments for Learning Styles and for Activities Assessment}

Below, we discuss other tools that were used during the course that are relevant to the objectives proposed in this work, both for analyzing student learning styles as well as to obtain information about how students grasp and assess the different activities.

First, two different questionnaires were used to identify and analyze student learning styles, namely:

- The CHAEA questionnaire [24], consisting in 80 statements $(20$ for each style: active, reflective, theoretical and pragmatic), scored on a dichotomous scale $(+/$ agree or $-/$ disagree). The score obtained corresponds to the preference, which is graphically represented on a two-axis scale, creating what the authors call a "diamond".

- Felder's Index [32]: this index consists of 44 dual selection statements that allow establishing preference in two-pole scales between: Active/Reflective, Sensing/Intuitive, Visual/Verbal and Sequential/Global.

Similarly, other opinion and assessment surveys were also used to obtain useful information to help achieve the goals proposed, namely:

- Completing an individual questionnaire to assess team work and the conceptual map generated by the group.

- Completing an assessment survey in relation to the conceptual maps produced individually about the resources created by other groups.

\section{RESULTS}

In this section, the results obtained are discussed from the point of view of the objectives described in Section III above.

\section{A. Objective 1: Learning indicators interpretation}

As regards the first objective, Table I lists the learning indicators obtained by students when going through the sequence of activities shown in Figure 1, more specifically, as a result of Phase 2 based on autonomous learning. These indicators are automatically calculated by $M$-eRoDes using the self-assessment procedure based on conceptual map similarity.

Each column in Table I represents the indicators obtained by each student, and the rows correspond to the resources used in the teaching and learning process (specifically, seven different resources were created as part of this experience; see the note in Table I). For each resource, the global result and the indicators for concept similarity and relation similarity are shown. Quantitative results are automatically color-coded to help students and educators interpret them - red means insufficient learning; yellow, learning could be improved; and green, adequate learning. This color-coding is configurable and it is based on the experience with previous courses. Lastly, the checkboxes marked with an " $\mathrm{X}$ " indicate that the student did not complete the activity corresponding to that resource (in this case, because the student was a member of the group that created the resource in Phase 1 of the activity).

TABLE I:

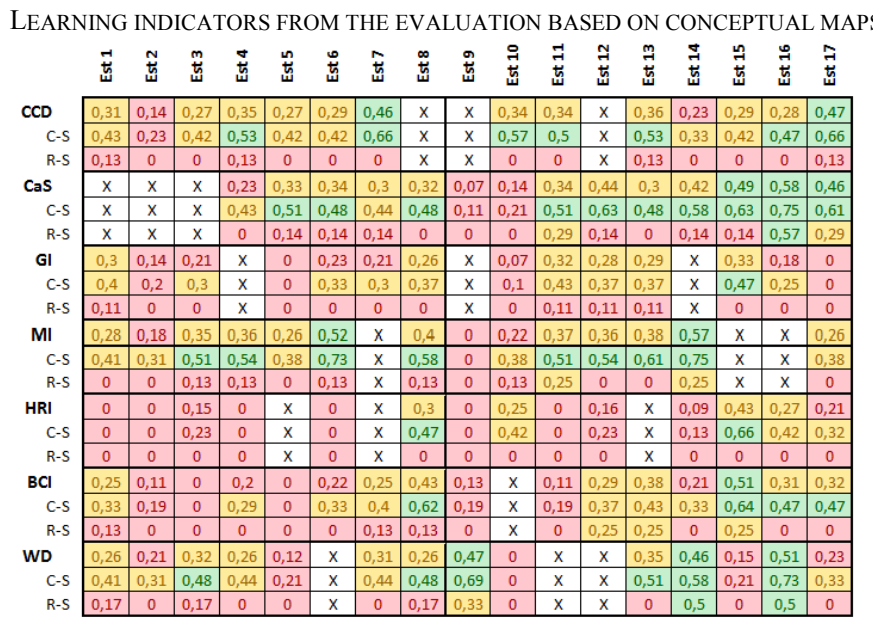

Note: Resource acronym meanings: CCD (Child-Centered Design), CaS (Context-aware Systems), GI (Gestural Interaction), MI (Multimodal Interaction), HRI (Human-Robot Interaction), BCI (Brain-Computer Interface) and WD (Wearable Devices). 
A global analysis of the indicators allows identifying certain problems in the teaching and learning process. On the one hand, those students that present mostly red indicators (e.g., students 2 and 9) are students who have not correctly worked with the learning resources or who have not been able to use conceptual maps to express what they learned. On the other hand, if the reference conceptual map is not correctly prepared, i.e., it does not represent the main ideas for its contents, then the corresponding resource would yield poor results (e.g., the "Human-Robot Interaction", HRI resource).

Another important issue derived from the indicators is that students are, in general, capable of identifying the key concepts presented by the resources (rows C-S, "ConceptSimilarity"), but they have significant trouble when they need to represent the relations among these concepts (rows R-S, "Relational-Similarity"). This experience has led us to the conclusion that the process of discovering relations and correctly representing them is complex and demands a greater level of student reflectiveness and maturity than what they currently have. Student ability and experience are also believed to play a role when working with conceptual maps; in this case, there were many students who had no prior experience using this type of activity oriented to represent knowledge.

Despite these difficulties, the use of this type of representation techniques forced students to reflect about what they learned, abstracting and contextualizing knowledge of interest for each specific resource. This additional effort strengthens the learning process itself. Also, in addition to providing learning indicators, M-eRoDes provides students with the reference conceptual map associated with each resource. Thus, they can visually compare their learning maps with the reference map and identify which knowledge (concepts, associations or contextual information) they did not consider to be relevant, reinforcing the feedback provided by the system. However, in future courses certain modifications may be introduced in the conceptual maps training offered to students and in the methodology used to create these maps, such as on-going training as an alternative to the single class that takes place when the course starts, or providing the students directly with the syntactic structure of the maps and have them just fill in the concepts, their relevance and relation labels.

\section{B. Objective 2: Easiness and usefulness assessment for the different activities}

As regards the second objective, the results obtained can be seen in tables II and III, which include the means, modes and deviations in opinions about the easiness and usefulness of the activities depicted in Fig. 1, as well as in relation to the master class and practical classes, which are also part of the subject dynamics. Student opinions were collected and analyzed using 6-level surveys, where 1 represents not easy/not useful and 6 represents very easy/very useful).
TABLE II

ACTIVITY EASINESS

\begin{tabular}{|l|l|l|l|l|}
\cline { 2 - 5 } \multicolumn{2}{l|}{} & Mean & Mode & Dev. \\
\hline 1.4 & Practical class at the Etopía center & 5.44 & 6 & 0.7 \\
\hline 1.12 & $\begin{array}{l}\text { Oral presentations or discussion } \\
\text { of works }\end{array}$ & 4.8 & 4 & 1.2 \\
\hline 1.3 & Group work & 4.65 & 5 & 1.09 \\
\hline 1.8 & $\begin{array}{l}\text { Paboratory practice } \\
\text { created by my group }\end{array}$ & 4.63 & 5 & 0.89 \\
\hline 1.10 & $\begin{array}{l}\text { Completing tests for videos } \\
\text { created by classmates }\end{array}$ & 4.55 & 5 & 0.94 \\
\hline 1.5 & $\begin{array}{l}\text { Searching for and selecting } \\
\text { material to prepare the video } \\
\text { script }\end{array}$ & 4.2 & 4 & 1.02 \\
\hline 1.1 & Attending to a master class & 4.18 & 4 & 0.88 \\
\hline 1.11 & Generating written reports & 4.15 & 5 & 1.26 \\
\hline 1.6 & Preparing video script (contents) & 4.1 & 5 & 1.07 \\
\hline 1.7 & Creating the video (technical) & 3.95 & 4 & 1.22 \\
\hline 1.9 & Creating conceptual maps & 3.5 & 3 & 1.39 \\
\hline
\end{tabular}

TABLE III

PERCEIVED USEFULNESS OF LEARNING ACTIVITIES

\begin{tabular}{|l|l|l|l|l|}
\cline { 3 - 5 } \multicolumn{2}{l|}{} & Mean & Mode & Dev. \\
\hline 2.1 & Attending to a master class & 4.76 & 5 & 0.97 \\
\hline 2.2 & Group work & 4.15 & 4 & 0.88 \\
\hline 2.3 & $\begin{array}{l}\text { Searching for and selecting } \\
\text { material to prepare the video script }\end{array}$ & 4.15 & 5 & 1.35 \\
\hline 2.7 & Laboratory practice & 4.11 & 5 & 1.33 \\
\hline 2.10 & $\begin{array}{l}\text { Creating the video (technical) } \\
\text { created by classmates }\end{array}$ & 4.11 & 5 & 1.33 \\
\hline 2.4 & Practical class at the Etopía center & 4 & 4 & 1.03 \\
\hline 2.12 & $\begin{array}{l}\text { Oral presentations or discussion of } \\
\text { works }\end{array}$ & 4 & 5 & 1.36 \\
\hline 2.6 & Preparing video script (contents) & 3.8 & 3 & 1.44 \\
\hline 2.11 & Generating written reports & 3.8 & 4 & 0.89 \\
\hline 2.9 & Creating conceptual maps & 3.75 & 4 & 1.41 \\
\hline 2.8 & $\begin{array}{l}\text { Preparing a test about the video } \\
\text { created by my group }\end{array}$ & 3.45 & 3 & 1.47 \\
& & & & 1.41 \\
\hline
\end{tabular}

In both tables, activities are sorted in descending order based on the mean value obtained for each of them. It should be noted that all activities in Table II start with "1", and all activities in Table III start with "2", which is the only difference in activity numbering between both tables.

Table II shows that the easiest activity and with the highest level of agreement (highest mode and lowest deviation) is activity 1.4 (Etopía), which is practical activity that involves going out of the campus and visiting an applied technology center. This is the only activity with a mode of 6 , in terms of easiness. However, it is the seventh in terms of usefulness.

Attending to master class (2.1) stands out for being perceived as highly valuable, with a reduced deviation as regards usefulness, as shown in Table III. Similarly, as shown in Table II, it is also highly valued for its easiness (mean = 4.18 , mode $=4$ ), even though it is on the eighth place in this regard.

Considering group work (2.2), it can be seen that both its mean and mode values are high (4.15 and 4, respectively), and 
it is the activity assessed with the highest level of agreement, since it has the lowest dispersion.

On the other hand, if both parameters (easiness and usefulness) are analyzed in parallel, it can be seen that only laboratory practices (1.3 and 2.3) and group work (1.2 and 2.2) are among the first four highest ranking activities.

As regards both activities, it should be noted that the level of agreement is higher in relation to laboratory practices (lower deviation) than in relation to usefulness (higher deviation). It is remarkable that it has been very highly valued both as regards easiness and usefulness, with a mode of 5 . The opposite happens with group work, where the lower deviation value corresponds to usefulness.

\section{Objective 3: Conceptual maps usefulness and ease-of- use assessment}

As regards the third objective, which focuses on the specific opinion of students about the easiness and usefulness of conceptual maps as representation and evaluation tool, using the same 6-level scale described above, the group assessed easy-of-use with a mean value of 3.5 , and usefulness with a mean value of 3.75 , with a value of 3 and 4 , respectively, for the mode. This indicates that, for the group, conceptual maps seem to be more useful than easy to use. A more in-depth analysis of these results indicates that $55 \%$ of the group found building these maps to be difficult (assessment between 1-3), while $60 \%$ of the group found maps useful (assessment between 4- 6).

If the relation between easiness and usefulness is analyzed individually, it can be observed that $30 \%$ of the students assessed both with a value of 5 or 6 , i.e., easy and useful, and almost the same proportion of students $(25 \%)$ considered that it was not easy or useful. Finally, $30 \%$ of the students indicate that they found it difficult but useful; and the remaining $15 \%$ found it easy to use but not useful.

The same as with the previous objective, students also assessed the 12 activities carried out during the course. In this regard, it can be seen that conceptual maps had the lowest scores for easiness, and second to last for usefulness.

However, based on individual surveys, the group assigned a high score to the activity of building conceptual maps as a group for their learning resource. The survey, which is divided in three sections, shows that:

- The teams followed the required learning strategies for creating the maps (identifying key concepts, structuring information, defining relations and chaining logic, etc.).
- Group work shows that students were able to define objectives and jointly plan the task, communicating fluidly and with equal participation.

- The group is highly satisfied with their learning, the appropriateness of the map created, working as a team, and the results obtained.

\section{Objective 4: Student learning style identification and analysis}

The fourth objective was studying student learning styles and identifying the preferred one, analyzing potential correlations with favorite activities.

The results of the group in the CHAEA questionnaire for each of the four learning styles, based on the scale established for the reference group, are presented in Table IV. The shaded cells indicate the values of the scale where the group mean is found for each style (Active $\bar{x}$ 9.9/ Reflective $\bar{X}$ 16.05/ Theoretical $\bar{x}$ 14.1/ Pragmatic $\bar{x}$ 12.75). Therefore, comparing these results with the scale in CHAEA for their reference group (technical courses of studies: Computer Science), it can be seen that the group scores lower than the mean as regards a preference for the active style. The group is within the mean for the reflective and pragmatic style, and it has a preference above the mean (categorized as high according to the reference table) for the theoretical style.

This points to a greater preference for working with structured situations that have a concrete goal. They prefer to work with data and models and establish connections between them. They need enough time to do this work rigorously. They like being able to question and test things out. They are logical and precise, they can work under intellectual pressure to solve a challenge, and they like untangling complex situations.

Table V can be used for a more detailed analysis, since it shows individual results. The first 17 students in this table are those from Table I, while the last 3 students filled in the learning style questionnaire but did not carry out the automatic evaluation tasks, which is why they were not included in Table I.

TABLE IV

RESULTS OBTAINED BY THE GROUP OF STUDENTS IN THE CHAEA SCALE FOR COMPUTER SCIENCE

\begin{tabular}{|c|c|c|c|c|c|}
\hline $\begin{array}{c}\text { Preference } \\
\text { for style... }\end{array}$ & $\begin{array}{c}\text { Very } \\
\text { low }\end{array}$ & Low & Moderate & High & $\begin{array}{c}\text { Very } \\
\text { high }\end{array}$ \\
\hline Active & $0-6$ & $7-9$ & $10-12$ & $13-15$ & $16-20$ \\
\hline Reflective & $0-10$ & $11-14$ & $15-17$ & 18 & $19-20$ \\
\hline Theoretical & $0-6$ & $7-9$ & $10-12$ & $13-15$ & $16-20$ \\
\hline Pragmatic & $0-8$ & $9-10$ & $11-13$ & $14-15$ & $16-20$ \\
\hline
\end{tabular}


TABLE V

COMPARATIVE RESULTS BY STUDENT BASED ON LEARNING STYLE SCALES

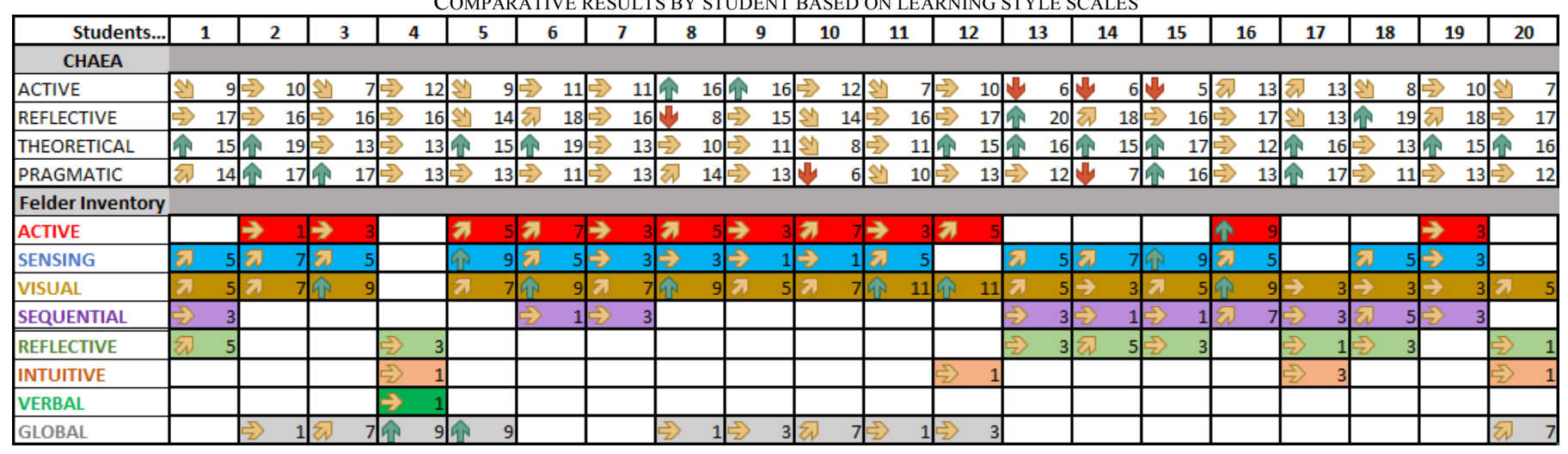

Note: Meaning of the arrows: an upwards, vertical arrow indicates a very high preference for this style; an upwards, diagonal arrow indicates high preference; a horizontal arrow indicates moderate preference; a downwards, diagonal arrow indicates low preference; and a downwards, vertical arrow indicates very low preference. For easier reading, the results corresponding to Felder and Silverman show only the resulting style, following the same method used in Felder's Index. It is obtained by subtracting the Active/Reflective, Sensing/Intuitive, Visual/Verbal and Sequential/Global pairs, considered as the ends of a gradient.

As regards group specific preferences, using CHAEA, the following stands out:

- The mean is high in the theoretical style, but it should also be noted that $59 \%$ of the students presented a "very high" preference, and $41 \%$ of them a "moderate" preference, with no "low" or "very low" occurrences.

- In both the reflective and pragmatic styles, there is a predominance of individuals with a moderate preference $(58 \%)$.

- The low incidence of the active style is noteworthy, with $45 \%$ for "low and very low", $35 \%$ for "moderate", and only $20 \%$ for "high and very high", which might indicate that students may have difficulties when trying new things, generating ideas, taking on risks, etc.

Felder's Index [26] yielded the following results as regards group preferences:

- The low incidence of the active style matches the data obtained with Felder and Silverman's questionnaire, with a predominance of a balance in the active-reflective pair with $60 \%$ (matching the result obtained with CHAEA).

- As regards the Sensing/Intuitive pair, results show $10 \%$ of a "very high" preference and $45 \%$ of a "high" preference for the sensing style; it should also be noted that in neither case there is a high preference for the intuitive style. The sensing style defines characteristics that are similar to those corresponding to the theoretical style in CHAEA, so the results here point in the same direction.

- There is a relevant preference for a visual style $(35 \%$ "very high" and 40\% "high") and, more interestingly, there is no preference for a verbal style. Therefore, students will use as reference what they see, which will be what they remember best (images, charts, diagrams, timelines, movies, demonstrations...); rather than verbal information, which they have more difficulty in remembering.

- As regards the Sequential/Global pair, the results obtained were not relevant.

These results partially match the research in [26] with
Engineering students. This is also applicable to the sensing and visual preference, and does not match the preference for an active style, as already mentioned.

Finally, a potential correlation between the use of conceptual maps and the results obtained around student learning styles is analyzed. From the point of view of CHAEA, since the use of conceptual maps is favored by the fact that students have a high or very high preference for the theoretical and pragmatic styles, in general terms, presenting ideas in a structured way could be more motivating than the fact that they can be immediately applied and transferred to the real world. On the other and, based on Felder's work [26], conceptual maps favor a visual and sensing style, so using them would be in agreement with the idea proposed by the authors that the teaching style should connect with these characteristics of the students. In this sense, even though conceptual maps were not considered by students to be one of the easier or more useful activities, using them would reinforce the work done through visual channels, although not as much as creating learning resources such as videos.

Also, a correlation can be established between the good result obtained for the activity "Attending to a master class" and the fact that the group obtained a high score for the theoretical style.

\section{CONCLUSIONS}

In the context of an Engineering subject, the students created their own learning resources and used conceptual maps to express what they wanted to teach and what they learned when working with these resources. To this end, a tool called $M-e R o D e s$ was used which, unlike other learning tutors, supports collaborative activities and provides automatic feedback to students that allows applying formative evaluation throughout the learning process.

Specifically, the possibilities of using conceptual maps as strategy for representing and assessing the knowledge acquired by students have been analyzed. Potential links to the learning styles of the students attending the course have also been considered. These styles were identified using 
questionnaires that are well known in academic literature.

The first conclusion is that students value the strategies developed, and are satisfied in particular with the resources created and the results obtained. These perceptions and opinions are in agreement with the results of the learning styles questionnaires, which indicate that the students value visual and sensing aspects, meaning that they consider multimedia resources attractive for learning.

On the other hand, students do not find conceptual maps easy to build. The moderate preference for the pragmatic style, which matches the analysis of university students done by the authors of CHAEA [24, 28], could affect this perception. In this regard, more work needs to be done to find ways to make the task of building these maps easier for the students. However, they are aware of the usefulness of these knowledge structures and, therefore, of their role in knowledge exchange and the assessment process used in M-eRoDes.

In any case, it should be noted that the fact that one activity requires more effort on the part of the students due to their own learning style does not mean that educators should avoid such activity. Quite the opposite in fact, since a greater level of difficulty could simply be a greater challenge for this group that could eventually help them develop abilities to express knowledge using the strategy. CHAEA's model itself states that students should actively work to learn under any circumstances and with any learning activity, regardless of their preference. Working in this direction can open doors to strengthen students' self-regulation and autonomy processes.

Along this same line, it should be noted that the friendliness and usefulness that the group attributes to the theoretical lecture should not justify either going back to this type of methodology as central element in the process, but rather value it as a supplementary activity.

Identifying students' learning styles at the beginning of the teaching and learning process is an option that should be studied in greater detail, and it should be useful to educators $[33,34]$, since they would be able to provide greater support for those activities that are further away from the natural way in which the group learns.

As regards study limitations, it should be noted that we have worked with only one group/class, which limits the possibilities for generalizing the issues observed. Also, there were other, non-controlled variables that may have affected student assessments. The most relevant ones could be: specific characteristics of the group, the efficacy of the initial introductory training to the use of conceptual maps, and variables related to students' personality.

In any case, and to sum up, from a prospective standpoint, creating audiovisual resources and using conceptual maps is not something that is specific to Computer Science. Therefore, this proposal could be applied to subjects taught in other disciplines, especially those in the final years of graduate and master degrees. The path traveled by the students has helped them reflect on their own learning, that of their classmates, and their active participation in the learning process, and it has allowed educators to assess the strategies used based on the group of students. Similarly, the role of the tool M-eRoDes also stands out, since it proved to be a good support for this model and allows for reusability by both students and educators.

\section{ACKNOWLEDGMENTS}

This work has been funded by the PIIDUZ_16_047 and PIIDUZ_17_078 projects, both from the Teaching Innovation Program of the University of Zaragoza.

\section{REFERENCES}

[1] Pintrich, P. R. "The role of goal orientation in self-regulated learning". In M. Boekaerts, P. R. Pintrich, \& M. Zeidner (Eds.), Handbook of selfregulation, San Diego, CA: Academic Press, pp. 452-502, 2000

[2] Baldassarri S., Álvarez P. "M-eRoDes: involucrando a los estudiantes en la creación y evaluación colaborativa de objetos de aprendizaje”. XXII Jornadas sobre la Enseñanza Universitaria de la Informática (Jenui'2016), pp. 195-202, 2016.

[3] Coma T., Aguelo A., Alvarez P., Sanz C., Baldassarri S. "Estilos de aprendizaje en actividades basadas en el uso de mapas conceptuales", IV Congreso Internacional sobre Aprendizaje, Innovación y Competitividad (CINAIC 2017), pp. 503-508, 2017, DOI: 10.26754/CINAIC.2017.000001_106.

[4] Al-Nakhal, M., Abu Naser, S.S. "Adaptive Intelligent Tutoring System for Learning Computer Theory". European Academic Research, vol. 4, no. 10 , pp. $8770-8782,2017$

[5] Paiva R.C., Ferreira M.S., Frade M.M. "Intelligent tutorial system based on personalized system of instruction to teach or remind mathematical concepts". Journal of Computer Assisted Learning, vol. 33, no. 4, pp. 370-381, 2017.

[6] Ahmed, M.U., Sangi, N., Mahmood, A. "A Model of Adaptive ELearning in an ODL Environment". Mehran University Research Journal of Engineering and Technology, vol. 37, no. 2, pp. 367-382, 2018.

[7] Myneni, L.S., Narayanan, N.H., Rebello, S., Rouinfar, A., Pumtambekar, S. "An Interactive and Intelligent Learning System for Physics Education”. IEEE Transactions on Learning Technologies, vol. 6, no. 3, pp. 228-239, 2013.

[8] Muhammad, A., Zhou, Q., Beydoun, G., Xu, D., Shen, J. "Learning path adaptation in online learning systems". IEEE 20th International Conference on Computer Supported Cooperative Work in Design (CSCWD-2016), pp. 421-426, 2016.

[9] Van Seters, J.R., Ossevoort, M.A., Tramper, J., Goedhart, M.J. “The influence of student characteristics on the use of adaptive e-learning material", Computers \& Education, vol. 8, no. 3, pp.942-952, 2012.

[10] Lekkas, Z., Germanakos, P., Tsianos, N., Mourlas, C., Samaras, G. "Personality and Emotion as Determinants of the Learning Experience: How Affective Behavior Interacts with Various Components of the Learning Process", Human-Computer Interaction. Applications and Services, Springer Berlin Heidelberg, pp. 418-427, 2013.

[11] Klašnja-Milićević, A., Vesin, B., Ivanović, M., Budimac, Z. "ELearning personalization based on hybrid recommendation strategy and learning style identification", Computers \& Education, vol. 56, no. 3., pp. 885-899, 2011.

[12] Suebnukarn, S., Haddawy, P. "A Collaborative Intelligent Tutoring System for Medical Problem-based Learning", Proceedings of the 9th International Conference on Intelligent User Interfaces (IUI 2004), pp. 14-21, 2004.

[13] Trumpower, D., Filiz, M., Sarwar, G. S. "Assessment for Learning Using Digital Knowledge Maps”. Springer, pp. 221-237, 2014

[14] Kandil Ingeç, S. "Analysing Concept Maps as an Assessment Tool in Teaching Physics and Comparison with the Achievement Tests". International Journal of Science Education, vol. 31, no. 14, pp. 1897$1915,2009$.

[15] Clariana, R.B. "Deriving Individual and Group Knowledge Structure from Network Diagrams and from Essays". Boston, MA, Springer US, 2010, pp. 117-130.

[16] Awati, A. S., Dixit, A. "Automated evaluation framework for student learning using concept maps". International Journal of Advance Research, Ideas and Innovations in Technology, 3(1), pp. 452-461, 2017.

[17] Anohina-Naumeca, A., Grundspenkis, J., Strautmane, M. "The concept map-based assessment system: functional capabilities, evolution, and 
experimental results". International Journal of Continuing Engineering Education and Life-Long Learning, 21(4), pp. 308-327, 2011.

[18] Gouli, E., Gogoulou, A., Papanikolaou, K., Grigoriadou, M. "Evaluating learner's knowledge level on concept mapping task". International Conference on Advanced Learning Technologies (ICALT'05), pp. 424428,2005

[19] Lin, S.C., Chang, K.E., Sung, Y.T., Chen, G.D. "A new structural knowledge assessment based on weighted concept maps", International Conference on Computers in Education, 1, pp. 679-680, 2002.

[20] Filiz, M., Trumpower, D., Vanapalli, A. "Exploring the mobile structural assessment tool: Concept maps for learning website". Revista Colombiana de Estadística, Current Topics in Statistical Graphics, 37(2), pp. 297-317, 2014.

[21] Bobadilla S, Cardoso Jiménez D, Carreno Saucedo L, Márquez Gómez JO. Estilos de aprendizaje en estudiantes de la licenciatura en psicología del centro universitario UAEM Temascaltepec, 2016. RIDE Revista Iberoamericana para la Investigación y el Desarrollo Educativo, 2017;7:34-50. 3 .

[22] Kolb, D. "Experiential Learning: Experience as the source of Learning and Development". Englewood Cliffs, New Jersey: Prentice-Hall, 1984.

[23] Kolb D.A. Experiential learning: Experience as the source of learning and development. United States of America: Pearson Education, Inc, $20152^{\text {a }} \mathrm{Ed}$.

[24] Alonso, C., Gallego, D., Honey, P. "Los Estilos de Aprendizaje. Procedimientos de diagnóstico y mejora". Bilbao: Ediciones Mensajero. Universidad de Deusto, 1994.

[25] Lugo, J., Rodríguez Hernández, G., Luna, E. "El cuestionario de estilos de aprendizaje CHAEA y la escala de estrategias de aprendizaje ACRA como herramienta potencial para la tutoría académica". Revista de Estilos de Aprendizaje, 10 (10), pp. 148-171, 2012.

[26] Felder, R.M., Silverman, L.K. "Learning and Teaching Styles in Engineering Education”. Engr. Education, 78(7), pp. 674-681, 1988.

[27] Camarero F., Martín del Buey F. y Herrero, J. "Estilos y estrategias de aprendizaje en estudiantes universitarios"Psicothema, vol. 12, No. 4, pp. 615-622, 2000.

[28] Alonso, C.M. (1992) "Estilos de aprendizaje: Análisis y Diagnóstico en Estudiantes Universitarios". vol. I y II. Madrid: Editorial Universidad Complutense, 1992.

[29] Kumar A., Singh N, Jyothi Ahuja, N. "Learning styles based adaptive intelligent tutoring systems: document analysis of articles published between 2001 and 2016". International Journal of Cognitive Research in Science, Engineering and Education, vol. 5, No. 2, pp. 83-98, 2017.

[30] Baldassarri S., Álvarez P. "Collaborative learning based on semantic technologies: An experience in computer science engineering". The 9th annual International Conference on Education and New Learning Technologies (EDULEARN 2017), Barcelona, Spain, 2017.

[31] Álvarez P., Baldassarri S. "eRoDes: a Web-based framework for the development of semantic-enhanced learning objects". The Eleventh International Conference on Internet and Web Applications and Services (ICIW 2016), pp. 1-6, 2016.

[32] Manual de estilos de aprendizaje. "Material autoinstruccional para docentes y orientadores educativos (2017, 19 Junio)". Available at http://biblioteca.ucv.cl/site/colecciones/manuales_u/Manual_Estilos_de_ Aprendizaje_2004.pdf

[33] Rodríguez $\overline{\mathrm{H}}$, Pirul J, Robles J, Pérez L, Vásquez E, Galaz I, et al. Análisis de los estilos de aprendizaje en alumnos de Medicina de la Universidad de Chile. Educación Médica, 2017.

[34] Hernández RM. La estrategia didáctica frente a los estilos de aprendizaje en la educación superior. Educ Med. 2018. https://doi.org/10.1016/j.edumed.2017.10.034

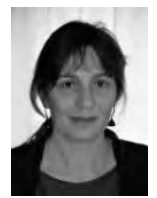

Teresa Coma Roselló. Ph.D. in Psychology and Learning from the University of Zaragoza (UZ) since 2016. Bachelor's Degree in Social Pedagogy from the Universidad Autónoma of Barcelona (UAB) and Diploma in Special Education Teaching from the University of Zaragoza. Master in Psychological Intervention with $\mathrm{DBM} \circledast{ }^{\circledR}$ by the University of Valencia (UV). Associate Professor of the Department of Psychology and Sociology, Social Psychology area of the University of Zaragoza since 2006. Advisor to the Chair of Cooperation for Development and Member of the Research Group on Advanced Interfaces /AffectiveLab at the University of Zaragoza and the International Research and Development Group TEIAS. Lines of research: orientation in learning processes, empathy, participation and teamwork, communication, performance management and inclusion. Participating in various research and teaching innovation projects.

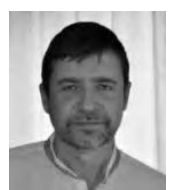

Antonio Aguelo Arguis. Ph.D. in Sociology from the University of Zaragoza (UZ) since 2011. Degree in Social Pedagogy from the Universidad Autónoma of Barcelona (UAB) and Diploma in Special Education Teaching from the University of Zaragoza. Associate Professor of Social Psychology at the Department of Psychology and Sociology of the University of Zaragoza since 2001. Member of the Research Group in Advanced Interfaces /AffectiveLab of the University of Zaragoza and the International Research and Development Group TEIAS. Lines of research: performance management, competencies, teamwork, emotional intelligence and empathy. Participating in various research and teaching innovation projects.

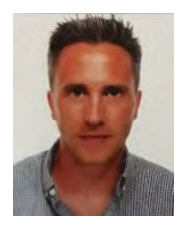

Pedro Álvarez received the Ph.D. degree in Computer Science Engineering from the University of Zaragoza, Zaragoza, Spain, in 2004. He works as Associate Professor at this University, since 2000. His current research interests focus on two main challenges. First, on integration problems of network-based systems (cloud-based and service-based systems, mainly) and the use of novel techniques and methodologies for solving them. And, secondly, on the application of formal analysis techniques to mine event logs and databases (in the domain of ecommerce, e-learning, cybersecurity, or health, for example). Nowadays, he leads the Research Group in Distributed Computing (DisCo) which is composed by more than 15 senior researches. On the other hand, Pedro has participated in more than 20 research project, being the lead researcher in 7 of them. The research results of these projects have been published in more than 100 international papers in different journals of his research field.

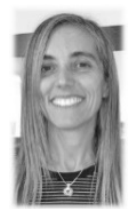

Cecilia Sanz. Received a B.Sc. in Computer Science in 1996 and a Ph.D in Computer Science in 2002 from National University of La Plata, Buenos Aires, Argentina. Since 2013, she works as a full time Titular Professor at this University. She is a researcher of the Scientific Research Commission (CIC). She is a research member of the Institute of Research in Computer Science III-LIDI, where she leads and participate in numerous projects either in national and international scope. Since 2009, she is the Director of the Master of IT and Education at the Computer Science School (UNLP).Her research interests include ICT and Education, Collaborative Work Systems and Human Computer interaction in educational scenarios. She has been published the results of these researches in diverse international conferences and journals.

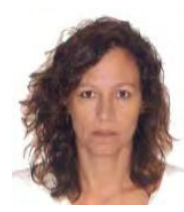

Sandra Baldassarri (M'99-SM'03) received a B.Sc. in Computer Science from University of Buenos Aires, Argentina, in 1992 and a Ph.D. in Computer Science Engineering from the University of Zaragoza, Spain, in 2004. From 1996, she is Assistant Professor in Computer Science Department at the University of Zaragoza (Spain) and founder member of the AffectiveLab of the Advanced Computer Graphics Group (GIGA) at the University of Zaragoza. Her research interests include virtual humans, affective computing, multimodal interfaces, tangible and natural interaction, and their application in educational fields. In these areas she published a numerous papers in conferences and journals and participates as part of the scientific and organizer committees of several Human Computer Interaction national and international conferences. She has participated in many research projects, as well as teaching innovation projects, either in national and international scopes. 